\title{
A TRANSPARÊNCIA DIVINA NA TRAMA DA CRIAÇÃO
}

\author{
The divine transparency in \\ the woof of the Creation
}

\section{Sinivaldo S. Tavares, OFM}

Frade franciscano com doutorado em Teologia Sistemática pela Pontificia Università Antonianum de Roma (1998), Professor de Teologia Sistemática na Faculdade de Teologia do Instituto Teológico Franciscano de Petrópolis (RJ), Coordenador do Curso de Pós-Graduação lato sensu "Espiritualidade, Ecologia e Educação: uma abordagem transdisciplinar” e coordenador do Master em Evangelização "Cenários contemporâneos e Perspectiva Franciscana”, Petrópolis, RJ - Brasil, e-mail: sinivaldo@itf.org.br

\section{Resumo}

Acolhendo os desafios postos pela "crise ecológica", o autor se pergunta: é viável continuarmos na direção imposta pelo paradigma antropocêntrico moderno? Continuar legitimando esse paradigma civilizacional seria uma posição eticamente responsável por parte da teologia? Interpelado por essa indagação de fundo, o autor procura reconstruir um discurso acerca da Criação que seja, para todos os efeitos, contemporâneo e, ao mesmo tempo, genuinamente cristão. Ele contempla a complexidade da Criação à luz do Mistério da Trindade Santíssima: 
como expressão do inusitado e gratuito dom do Pai, como o corpo cósmico de Cristo e como a morada do Espírito Santo. Interpela-nos a assumir nossa intransferível responsabilidade face à inteira Criação, que se encontra ameaçada, em termos de acolhida e de discernimento: acolhida do inaudito dom da vida e discernimento das pegadas do Cristo presentes na Criação e dos gemidos inefáveis do Spiritus Creator que ecoam por entre os meandros sutis do universo. E conclui explicitando a singularidade do discurso cristão acerca da Criação em termos de transparência divina na trama da Criação.

Palavras-chave: Criação. Dom de Deus. Corpo cósmico de Cristo. Morada do Espírito Santo.

\section{Abstract}

Welcoming the challenges posed by the "ecological crisis", the author asks: is still viable in the direction imposed by modern anthropocentric paradigm? Continue that legitimating paradigm civilization is ethically responsible for a part of theology? Informed by the question of substance, the author seeks to reconstruct a speech about creation is, for all purposes, contemporary and at the same time, genuinely Christian. It addresses the complexity of creation in light of Holy Trinity mystery: as an expression of unusual free gift of the Father, as the cosmic body of Christ and how to address the Holy Spirit. Concerns us to take our responsibility towards the entire non Creation, which is threatened in terms of accepted and discernment: accepted the gift of life and unprecedented discernment of Christ footsteps on Creation and Creator Spiritus unspeakable groans that echoed through the subtle intricacies of the universe. He concludes explaining the uniqueness of the Christian discourse about the Creation in terms of transparency in the divine drama of creation.

Keywords: Creation. Gift of God. Cosmic Christ body. Home of the Holy Spirit. 
Nosso intento é elaborar um discurso acerca da Criação que, acolhendo com responsabilidade os desafios provenientes da "crise ecológica", se proponha como genuinamente cristão e, por conseguinte, relevante para o ser humano neste início de século XXI. As conclusões do Painel Intergovernamental sobre Mudanças Climáticas (IPCC), publicadas em 2007 vieram confirmar o que já temíamos: o "aquecimento global”, provocado pelo modo de produção e de consumo humanos, representa um dado irreversível. Não se trata, infelizmente, de um alarme falso, mas sim de uma constatação baseada em dados empíricos recolhidos pelos milhares de cientistas espalhados em 130 países que compõem o IPCC, organismo ligado à ONU. Até então julgávamos ser suficiente preservar e cuidar da Terra com compreensão, compaixão e amor, atentos a não ultrapassar o limite intransponível que, uma vez transposto, modificaria o estado da Terra. A partir de agora, todavia, duas estratégias se nos apresentam com urgência: adaptar-se à nova situação e minorar os efeitos maléficos.

Esclarecedores são os dados divulgados em 2008 pelo Pnud (Programa das Nações Unidas para o Desenvolvimento) em seu "Relatório do Desenvolvimento Humano 2007-2008”, intitulado Combater a Mudança Climática: Solidariedade Humana num Mundo Dividido. O relatório alertanos para uma situação paradoxal: as populações mais pobres, justamente aquelas que contribuem de maneira desprezível ao aquecimento global, serão as maiores vítimas dos resultados imediatos da mudança no clima. Apenas 13\% da população do planeta são responsáveis por mais da metade da emissão dos gases de efeito estufa. Os EUA e a União Europeia juntos são responsáveis por 10 Gt das 29 Gt liberados anualmente em todo o planeta. O relatório mostra ainda que se cada pessoa pobre do Planeta levasse o mesmo estilo de vida de alto consumo de energia de um habitante médio dos EUA ou do Canadá, seriam necessários nove planetas para absorver a poluição. Com razão, dizia Gandhi: "A Terra possui recursos suficientes para prover às necessidades de todos, mas não à avidez de alguns".

O aquecimento global, segundo o mesmo relatório, desencadeará provavelmente um grande retrocesso no desenvolvimento e o total fracasso em implementar os "Objetivos de Desenvolvimento do Milênio" (ODM), acordados na ONU em 2000, para a redução da pobreza mundial. O arcebispo emérito da Cidade do Cabo, Desmond Tutu, referindo-se a essa situação, fala de um verdadeiro "Apartheid da Adaptação". Percebemos hoje, mais do que nunca, o caráter reducionista e profundamente excludente do 
paradigma civilizacional moderno. Daí a urgência de se articular o grito da Terra com o grito dos pobres. ${ }^{1}$

Face à realidade que acabamos de descrever, não podemos nos furtar às seguintes questões: é viável continuarmos nessa mesma direção imposta pelo paradigma antropocêntrico moderno? O que fazer para que essa "lógica" da acumulação e do consumo, de crescimento linear e desmedido, seja desmascarada como principal responsável pela depredação dos recursos naturais e pela ameaça de futuro do ser humano e do inteiro Planeta? Continuar legitimando esse paradigma civilizacional seria uma posição eticamente responsável por parte da Teologia?

Neste ano celebramos o $2^{\circ}$ centenário do nascimento de Charles Darwin e também os 150 anos da publicação de sua clássica obra “A origem das espécies” (1859). Todavia, como uma espécie de divisor de águas, o cientista britânico continua dividindo as opiniões acerca da origem da vida e de sua evolução. Em torno de sua pessoa e de suas posições assistimos hoje ao ressurgimento de novos fundamentalismos. De um lado, o fundamentalismo científico cujo representante mais conhecido é Richard Dawkins, ${ }^{2}$ corrente que se fundamenta, sobretudo, no evolucionismo de Darwin para justificar um certo “ateísmo militante”. ${ }^{3}$ De outro, o fundamentalismo religioso: grupos contrários à teoria darwiniana da evolução como, por exemplo, os fautores do Criacionismo e, mais recentemente ainda, os adeptos do assim chamado "Intelligent Design”. ${ }^{4}$

Tanto os criacionistas quanto os defensores do "Intelligent Design" assumem, em última instância, posturas visivelmente fundamentalistas. Estes últimos julgam ter provas científicas das contínuas intervenções de Deus, por eles considerado o "intelligent Designer", que explicariam os saltos e as

1 As várias publicações de L. BOFF, dentre as quais destacamos 1995 [com ampla bibliografia]; WILSON, 2008.

2 Dawkins se tornou mundialmente conhecido por sua polêmica e controversa publicação The God delusion (traduzida em Português como Deus, um delírio. São Paulo: Companhia das Letras, 2007).

3 Os principais representantes desse grupo são: Richard Dawkins, Daniel Dennett, Sam Harris e Christopher Hitchens. E as publicações mais conhecidas desses autores que se inscrevem no movimento por eles mesmos denominado de "Ateísmo militante" são: The God delusion (R. Dawkins), Breaking the Spell (D. Dennett), The End of Faith e Letter to a Christian Nation (S. Harris) e God is not great: How Religion Poisons Everything (Ch. Hitche).

4 DEMSKI, 1999; BEHE, 1996.

Rev. Pistis Prax., Teol. Pastor., Curitiba, v. 1, n. 2, p. 339-354, jul./dez. 2009 
incongruências perceptíveis na irredutível complexidade da natureza. No caso específico da criação, ambos defendem uma concepção intervencionista do Criador. Deus seria considerado como o fundamento de tudo quanto existe e, portanto, situando-se fora da criação, interviria em alguns de seus momentos cruciais para garantir a harmonia e a estabilidade das criaturas e seus inerentes processos. Nesse sentido, essas representações do Criador se inserem no rol de outras imagens típicas da Modernidade, tais como: a do arquiteto e a do relojoeiro. A despeito de ambos os fundamentalismos, adverte-se também um vigoroso movimento que, acolhendo as interpelações lançadas por Darwin, procura reconstruir um discurso acerca da Criação que seja, para todos os efeitos, contemporâneo. ${ }^{5}$ Teilhard de Chardin costumava dizer que, após Darwin, Deus precisava deixar de ser visto apenas como Alfa (o começo de tudo) e mais como Ômega (a destinação última do universo).

Isto pressuposto, torna-se urgente para nós cristãos elaborar uma “teologia da criação” que faça jus à gravidade dos desafios que nos são postos pela atual conjuntura. ${ }^{6}$ Essa nova "teologia da criação" será fruto, em primeiro lugar, da releitura dos relatos bíblicos da criação. ${ }^{7} \mathrm{E}$ o intuito desta releitura será resgatar a singularidade do ser humano não operando uma separação sua das demais criaturas, mas, ao contrário, potencializando as inter e retrorrelações que o ligam intensa e intimamente a essa imensa e complexa "teia da vida" (CAPRA, 2000). Ademais, essa nova “teologia da criação” ensaiará concepções igualmente novas de Deus, do ser humano e das outras criaturas a partir de uma radical inversão dos processos de redenção e criação. ${ }^{8}$ Salientará, por conseguinte, a necessidade de se superar toda sorte de dualismo extrinsecista como caminho privilegiado de se compreender a inteira realidade como uma complexa teia. Qual teia de relações, as distintas singularidades aparecerão melhor na medida em que explorarmos ao máximo as íntimas interconexões que as mantêm unidas nessa complexidade do real.

5 ARNOULD, 1996, 1998; HAUGHT, 2006.

6 É o que intentamos fazer de forma mais detalhada em duas de nossas publicações recentes: "Os vestígios da Trindade na trama da Criação", em TAVARES, 2007, p. 192-210; TAVARES, 2008. p. 772-806.

7 A este propósito, ver REIMER, 2006; MESTER; OROFINO, apud SOTER, 2008, p. 11-21.

8 Consultem-se os seguintes trabalhos que se inserem nessa busca de uma teologia da Criação em diálogo com as ciências: LAMBERT, 1999; KÜNG, 2007; MOLTMANN, 2007; CAPRA; STEINDL-RAST, 2000.

Rev. Pistis Prax., Teol. Pastor., Curitiba, v. 1, n. 2, p. 339-354, jul./dez. 2009 


\section{A criação na perspectiva cristã}

Somos queridos por um Deus que é Pai e que nos cria mediante sua contundente Palavra, no vigor de seu Espírito. Isto significa que nossa existência, em última análise, constitui uma interpelação de Deus. Começamos a existir no contexto de um diálogo prévio e, portanto, constitutivo da nossa inalienável singularidade. Fomos constituídos por Deus, no momento mesmo da Criação, como seus potenciais interlocutores: ouvintes de Sua Palavra, na predisposição a compreender seus desígnios e a corresponder a suas interpelações, encarnandoos na própria vida. Existimos como criaturas, predispostas ao diálogo, porque convocadas ao encontro e à comunhão com o Criador. Mas essa palavra instauradora de diálogo é uma palavra propiciada pelo Espírito e, portanto, tornada fecunda por ele. Nossa vida emerge a partir da fecundidade do Espírito, vale dizer, sentimo-nos movidos no ritmo do Espírito de Deus. Isso significa que fomos queridos como criaturas entusiasmadas, por possuirmos, como exprime sua própria etimologia, um “deus dentro de nós”.

Reconhecendo a existência como interpelação do Criador porque, em última instância, uma in-habitação amorosa de Seu Espírito, nós a concebemos como uma contínua resposta e um constante exercício de acolhida terna e hospitaleira. Neste sentido, sentimos que a vida não é fruto de nossa iniciativa. Ela não começa, de fato, conosco. Ela é sempre resposta, e por isso mesmo, não se pode viver senão responsavelmente, acolhendo a própria existência como um exercício perene de responsabilidade, melhor dizendo, de corresponsabilidade. Pois, assim como nós não apenas vivemos, mas, convivemos com as pessoas e com as demais criaturas, da mesma forma não apenas respondemos, mas correspondemos, numa experiência de singular solidariedade, às interpelações que o Criador, através de sua Palavra e no Seu Espírito, nos lança em meio à complexidade das relações interpessoais e históricas, através das fibras mais íntimas da inteira realidade criada e ainda a partir da interioridade mais profunda de cada um de nós.

Com base em tal pressuposto, considerar a Criação como obra do Deus trino e uno significa contemplá-la como inusitado dom do Pai e, por extensão, como “corpo místico de Cristo” e “morada do Espírito Santo”. Nossa responsabilidade face à inteira Criação se exprime, portanto, na acolhida do inusitado dom do Pai e no discernimento das pegadas do Cristo presentes na trama da Criação e nos gemidos inefáveis do Spiritus Creator que ecoam por entre os meandros sutis do universo.

Rev. Pistis Prax., Teol. Pastor., Curitiba, v. 1, n. 2, p. 339-354, jul./dez. 2009 


\section{A criação como inusitado dom do Pai}

O termo Criação remete à experiência do dom e da gratuidade divinas. Dizer criação pressupõe a consciência da relação primordial entre Criador e criatura. Neste sentido, criação difere substancialmente de termos como, por exemplo, natureza ou cosmos. Ao nos reconhecermos criaturas, exprimimos a consciência de que a vida se nos afigura como oferecida gratuitamente. Poderíamos existir de outro modo ou sequer existir. E, no entanto, existimos. Portanto, o nosso existir revela um querer, uma intencionalidade, primários. Fomos queridos por alguém, por um Criador, e, portanto, passamos a existir. Não são, a rigor, necessidades intrínsecas que justificam nossa existência como tal. O que de fato testemunhamos é que somos queridos por alguém que deseja que existamos. E este alguém nos quer assim como somos. Também aquelas circunstâncias que caracterizam nossa existência são queridas como tais pelo Criador e correspondem, em última instância, a uma intencionalidade e querer gratuitos dele.

Não existem, portanto, explicações que deem conta do porquê de nossa existência. E aqui, precisamente, nosso Criador se revela como Absoluto, manifestando assim sua radical diferença face ao caráter intrinsecamente contingente de suas criaturas. O Criador não está vinculado a nada. Não existe nada fora de Deus que o possa condicionar. Ele é o Absoluto por excelência. E seu querer e agir são absolutamente gratuitos. O fio condutor, portanto, que atravessa a inteira realidade criada é constituído pela experiência da gratuidade em todas as suas expressões. Não existem, a rigor, leis ou relações necessárias que caracterizam a relação entre o Criador e suas criaturas. E, por esta razão, estão descartadas todas as tentativas de encontrar explicações lógicas e necessárias que deem razões à existência nossa e das demais criaturas.

Permeia a complexidade de tudo quando existe a gratuidade amorosa do Criador que se revela mediante um querer gracioso, caracterizado pelo cuidado e pelo enternecimento para com cada criatura e para com a inteira realidade criada. Este querer divino instaura de maneira consistente as legítimas buscas de sentido. A preocupação maior e mais fundamental do ser humano passa a ser então auscultar as interpelações do Criador inscritas em sua mais recôndita interioridade, no seio das relações interpessoais, nos meandros sutis da história e nas fibras mais íntimas da inteira realidade criada.

Rev. Pistis Prax., Teol. Pastor., Curitiba, v. 1, n. 2, p. 339-354, jul./dez. 2009 
Porque expressão do querer mais íntimo de um Pai que deseja criaturas para poder instaurar com elas relações de comunhão, a criação se revela como o palco da trama amorosa e, por isso mesmo, dramática do amor esponsal entre Deus e suas criaturas. Somos, enquanto criaturas, radicalmente diferentes do criador. Somos diferentes não para selar nossa irremissível separação; mas, ao contrário, para nos decidirmos livre e conscientemente pela relação, fomentando assim o encontro e tecendo teias de comunhão.

\section{A criação como corpo cósmico de Cristo}

A consideração acerca da intrínseca dimensão cósmica do Mistério da Encarnação do Verbo da Vida resulta não só plausível, mas particularmente relevante. Pois o mistério da Encarnação desvela, em última instância, a dimensão intimamente crística de toda a Criação. Segundo o testemunho das Escrituras sagradas, é por meio de Cristo que todas as coisas foram criadas e é por seu intermédio que todas as coisas, no vigor do Espírito, retornam a Deus Pai, único princípio e fim da criação. A relação que intercorre entre Jesus Cristo e a inteira criação é, portanto, dúplice: Ele é, por um verso, o primogênito de toda criatura e, por outro, o recapitulador da inteira realidade criada.

Pelo fato de que tudo quanto existe tenha sido criado n’Ele, por Ele, para Ele e por meio d’Ele, Jesus Cristo é, para todos os efeitos, o primogênito de toda criatura ( $\mathrm{Cl}$ 1,12-20). Cristo foi estabelecido pelo Pai como primogênito, porque, na verdade, somente n'Ele e por meio d'Ele a realidade inteira recupera seu verdadeiro sentido, seu significado mais profundo. A Encarnação emerge, então, como o sentido interno da criação. O sentido mais remoto, bem como a finalidade mais precípua da inteira realidade criada e de cada uma das criaturas, torna-se presente em Jesus Cristo, o primogênito entre muitos irmãos e irmãs. Compreendida assim, a Encarnação emerge como o horizonte de sentido no interior do qual repousa a complexidade do cosmos inteiro.

Se a Criação encontra sua razão de ser no mistério da Encarnação, então é também verdade que cada criatura, apesar de ínfima e insignificante, carrega em si, impressos, traços do Filho unigênito de Deus. Existe, neste sentido, um parentesco cósmico entre a inteira realidade criada e Jesus Cristo. O mistério do Verbo que se fez carne emerge como a perfeita explicitação desta íntima relação entre Deus e as criaturas, pois constitui o cumprimento do desígnio

Rev. Pistis Prax., Teol. Pastor., Curitiba, v. 1, n. 2, p. 339-354, jul./dez. 2009 
terno e amoroso do Criador. O mistério da Encarnação é, por excelência, expressão deste parentesco cósmico. Importa, neste caso, resgatar o valor perene desta dimensão intrinsecamente crística da inteira realidade criada.

Jesus Cristo é também o recapitulador universal, o reconciliador, conforme atesta o hino litúrgico de Ef 1,9-10,

E assim, ele nos deu a conhecer o mistério de seu plano e sua vontade, que propusera, em seu querer benevolente, na plenitude dos tempos realizar: o desígnio de, em Cristo, reunir todas as coisas: as da terra e as do céu.

Na qualidade de recapitulador, Ele levará a realidade inteira à plenitude, ao seu mais perfeito cumprimento. Isto significa dizer que é precisamente em Jesus Cristo que cada criatura encontra sua máxima realização. N’Ele e através d’Ele, a inteira realidade criada redescobre sua mais íntima vocação: criaturas de Deus, vocacionadas à comunhão plena com Ele. Em Cristo somos, de fato, predestinados a sermos pessoas humanas novas e a participar plenamente, juntamente com todas as criaturas que também serão transfiguradas, da glória do Deus criador (Rm 8,28s).

Enquanto prolongamento do mistério da Encarnação no aqui e agora de nossa experiência de fé, a Eucaristia constitui o memorial permanente daquele singular gesto de Deus de abraçar cada uma das criaturas e de envolvê-las todas num único abraço, em Jesus Cristo e por meio d'Ele. ${ }^{9}$ Trata-se da atitude do Cristo de assumir, purificando e elevando, cada uma das criaturas e as criaturas todas como parte integrante do seu corpo. Nada escapa à força da presença de Deus que, no seu Filho Jesus Cristo, alcança e penetra a inteira realidade criada, sem anular ou sufocar a singularidade de cada criatura.

A Eucaristia é, neste sentido, a prefiguração daquela realidade última que nos é dado esperar na fé, como promessa a ser cumprida. A realidade inteira será transfigurada na imagem bíblica dos novos céus e da nova terra e nós seremos transformados em seres humanos novos. Seremos, graças à íntima presença e ação do Espírito Santo, conformados cada vez mais à imagem e semelhança do Filho Unigênito do Pai. Da mesma forma a história e o inteiro cosmos serão transfigurados no Reino de Cristo, mediante a ação interior e eficaz do Espírito Santo que faz novas todas as coisas. Esta é a razão pela qual os textos do Segundo Testamento concebem a ação peculiar do Espírito de Deus como cristificação das pessoas, da história e da totalidade do cosmos.

9 O interessante estudo do Metropolita de Pérgamo: ZIZIOULAS, 2001.

Rev. Pistis Prax., Teol. Pastor., Curitiba, v. 1, n. 2, p. 339-354, jul./dez. 2009 
A corporeidade de Cristo, cuja memória se atualiza na celebração eucarística, é aquele nó capaz de unir mediante um vínculo estreito a existência de cada pessoa humana à história da inteira humanidade e ainda a todo o cosmos, e isto graças ao mistério da Encarnação do Filho de Deus. A expressão "corpo de Cristo” exprime os reais alcances desta inter-relação:

1) “Corpo de Cristo" enquanto expressão da vida de Jesus compreendida na totalidade de seus gestos e de suas palavras, culminados na entrega suprema do próprio corpo como verificação de sua inteira vida e da credibilidade de sua mensagem;

2) “Corpo de Cristo” entendido como cada pessoa que se conforma a Cristo, fazendo da própria vida uma oblação agradável a Deus;

3) “Corpo de Cristo” enquanto seu corpo histórico, a Igreja, comunidade daquelas pessoas que vivem a partir da consciência de que a pregação e o testemunho de Jesus, que adquiriram singular credibilidade na sua paixão, morte e ressurreição, continuam acontecendo na história das pessoas e do mundo;

4) “Corpo de Cristo” enquanto história que se quer construir, passo a passo, segundo os valores do Evangelho até a plena emergência do Reino de Deus;

5) "Corpo de Cristo”, enfim, enquanto inteira criação na sua complexidade, obra que o Pai realiza mediante o Espírito Santo que in-habita o inteiro cosmos, obra de transformação deste mundo no único “corpo de Cristo”.

Estas são as reais extensões do Corpo de Cristo propiciadas pela Ressurreição do Crucificado e pela Efusão do Espírito Santo sobre a comunidade dos fiéis. E é precisamente na celebração eucarística que experimentamos a relação íntima e profunda que existe entre estas distintas dimensões do "corpo de Cristo”. O corpo de Cristo eucarístico recolhe em si todas essas distintas dimensões lembradas anteriormente, respeitando e valorizando cada uma delas na sua singularidade, numa complexa tessitura em que os fios se entrelaçam como em uma teia. ${ }^{10}$

10 Para uma visão mais detalhada, remetemos ao nosso: "Eucaristia: pluralidade de dimensões na unidade do Mistério", TAVARES, 2003, p. 807-828.

Rev. Pistis Prax., Teol. Pastor., Curitiba, v. 1, n. 2, p. 339-354, jul./dez. 2009 
O antropólogo e místico jesuíta, Pe. Teihard de Chardin, autor do célebre texto A Missa sobre o Mundo, escreve: "Quando Cristo desce sacramentalmente em cada um de seus fiéis, não é apenas para conversar com ele [...]; quando ele diz, por meio do sacerdote: 'Hoc est corpus meum', essas palavras transbordam o pedaço de pão sobre o qual são pronunciadas: elas fazem nascer o Corpo místico inteiro. Para além da Hóstia transubstanciada, a operação sacerdotal estende-se ao próprio Cosmo. [...] A Matéria toda sofre, lenta e irresistivelmente, a grande Consagração" (CHARDIN, 1994, p. 15). ${ }^{11}$

João Paulo II, na encíclica Ecclesia de Eucharishia (2003, p. 11), em tom de confidência, escreve:

Este cenário tão variado das minhas celebrações eucarísticas faz-me experimentar intensamente o seu caráter universal e, por assim dizer, cósmico. Sim, cósmico! Porque, mesmo quando tem lugar no pequeno altar de uma igreja de aldeia, a Eucaristia é sempre celebrada, de certo modo, sobre o altar do mundo. Une o céu e a terra. Abraça e impregna toda a criação. O Filho de Deus fez-se homem para, num supremo ato de louvor, devolver toda a criação Àquele que a fez surgir do nada. Assim, Ele, o sumo e eterno Sacerdote, entrando com o sangue da sua cruz no santuário eterno, devolve ao Criador e Pai toda a criação redimida. [...] Verdadeiramente este é o mysterium fidei que se realiza na Eucaristia: o mundo saído das mãos de Deus criador volta a ele redimido por Cristo.

\section{A criação como morada do Espírito Santo}

As primeiras comunidades cristãs, que nos legaram sua experiência nos textos do Segundo Testamento, oferecem-nos um testemunho esclarecedor acerca da peculiar missão do Espírito Santo. Derramado generosamente sobre a comunidade dos fiéis para se fazer presente na história e no cosmos todo, o Espírito Santo opera lentamente a cristificação do gênero humano, da história e do cosmos inteiro. E, desta forma, Ele vai misteriosamente realizando a obra de reconciliação da inteira criação com Deus. O Espírito Santo, através da sua presença interior e misteriosa, vai transformando cada pessoa na imagem de Jesus Cristo. Presente no seio da igreja, Ele vai transformando a comunidade

11 Texto citado por Wildiers na introdução de CHARDIN, 1994, p. 15.

Rev. Pistis Prax., Teol. Pastor., Curitiba, v. 1, n. 2, p. 339-354, jul./dez. 2009 
dos fiéis no corpo de Cristo. Presente na história, o Espírito a fermenta desde dentro para que se transforme no Reino de Cristo. O Espírito Santo vai, enfim, atuando misticamente no coração do cosmos, vai despertando e explicitando cada vez mais na criação a saudade, a nostalgia da sua origem. E assim Ele opera a reconciliação da inteira criação, fazendo com que a mesma, contemplando o Cristo, seu paradigma, se reconheça na sua mais lídima dependência a seu Criador e Senhor e, assim, possa de novo ser reconduzida por Cristo, a Deus Pai, autor e princípio de tudo. E, assim, realizar-se-á o que diz o apóstolo Paulo: “Deus será tudo em todos” (1Cor 15,28).

O Espírito não age, porém, de maneira ostensiva de modo a manifestar sua presença mediante sinais e portentos extraordinários que se caracterizam pela nítida visibilidade. Ele age, por isso, interiormente, vale dizer, de dentro para fora. Ele penetra nas fibras mais íntimas da natureza, se insere nos meandros mais sutis da história e vem habitar no âmago mais recôndito do ser humano, para, a partir desta singular experiência de interioridade, iniciar sua lenta obra de santificação. Nem por isso sua presença é menos sentida nem tampouco sua ação carece de eficácia. Ao contrário, sua maneira interior e silenciosa de operar revela que toda autêntica transformação vem sempre de dentro para fora e não, ao contrário, de fora para dentro.

A singularidade do Espírito Santo se revela sobremaneira nesta sua peculiar maneira de se fazer presente e de agir interna e intimamente. Próprio do Espírito é ser ele mesmo no outro, no diverso de si. Assim, Ele se esconde no interior de cada uma de suas criaturas e na complexidade da história e do cosmos para potencializar no melhor dos modos as singularidades e alteridades que compõem as relações interpessoais, a trama da história e a complexa teia das criaturas todas. Mediante o seu Espírito, Deus se revela como a interioridade mais íntima de cada criatura e, portanto, da complexidade da Criação. Vindo a habitar na interioridade de cada criatura, o Espírito provoca o desabrochar da identidade mais própria dela; inserindo-se no coraçãopria dela, inserindo-se no coraçentidade mais pr, oEspa qualcomplexo da histrocidadeilho, faz com que o Ele assuma no melhor do da humanidade, Ele a fermenta desde o seu interior; e, finalmente, permeando o seio do cosmos, Ele potencializa ao máximo a riqueza e a pluralidade da criação propiciando a unidade profunda na mais diversificada pluralidade.

Ao contrário do que se poderia pensar, o Espírito não opera massificando. Seu modo peculiar de ser na alteridade mais radical de cada criatura, faz com que possam emergir as mais distintas e variadas singularidades no complexo e na trama

Rev. Pistis Prax., Teol. Pastor., Curitiba, v. 1, n. 2, p. 339-354, jul./dez. 2009 
de suas recíprocas alteridades. Ademais, o Espírito salienta sobremaneira as inter e retrorrelações que constituem as várias singularidades a partir de uma rede fecunda de reciprocidades entre singularidade e alteridade. E, assim fazendo, o Espírito Santo opera a mais perfeita comunhão entre as distintas singularidades, tornando-as disponíveis e potencializando-as ao encontro e à comunhão.

\section{Conclusão: a transparência divina na trama da criação}

Transcendente e imanente, na perspectiva cristã, se relacionam de maneira inusitada e deveras singular. Não seguem padrões dualistas típicos de tradições religiosas antigas nem de clássicas escolas de pensamento. No Ocidente, por exemplo, transcendente e imanente foram concebidos quase sempre como separados e opostos entre si. A alternativa a esta posição hegemônica acabou deslizando para o polo oposto: a fusão entre ambos, causando assim uma verdadeira confusão entre transcendente e imanente de modo a se sacrificar toda e qualquer distinção entre ambos.

Esta clássica polarização entre transcendente e imanente acabou gerando uma específica configuração: de um lado, temos as distintas formas de monoteísmo rígido com suas correspondentes cosmologias que desqualificam tudo o que é natural, histórico, humano e material. De outro, todavia, temos as conhecidas expressões de panteísmo que confundem criador com criatura, ocasionando uma série de incongruências.

Ao professar a fé no Deus trino e uno, as comunidades cristãs propiciam uma peculiar relação entre Transcendente e imanente. A profissão de fé no Deus Pai criador salienta o caráter absolutamente transcendente do Deus trino e uno. Ele é o criador absoluto, que cria sem pressupostos e sem condições, e, portanto, o Senhor de tudo quanto existe, selando assim sua irredutível transcendência face ao caráter contingencial de suas criaturas.

A profissão de fé no Filho unigênito de Deus que se encarnou, sublinha a singela solidariedade de Deus para com suas criaturas. O próprio Deus, na pessoa de seu Verbo encarnado, penetra no mais íntimo de uma de suas criaturas - o ser humano concreto e circunstanciado, Jesus de Nazaré - e, assim fazendo, instaura laços de profunda solidariedade com cada uma e com todas as criaturas. É o evento da mais radical irrupção do Todo no fragmento, da emergência do transcendente a partir do âmago mesmo da imanência.

Rev. Pistis Prax., Teol. Pastor., Curitiba, v. 1, n. 2, p. 339-354, jul./dez. 2009 
A profissão de fé no Espírito Santo, como evento da interiorização do próprio Deus no coração mesmo da matéria, da história, da corporalidade de suas criaturas, acena para a revelação do Deus trino e uno como a interioridade mais íntima do cosmos, da história e da vida de cada uma e de todas as criaturas.

Ocorre, portanto, dialetizar transcendência e imanência através da consideração do evento da interiorização do próprio Deus no coração mesmo da matéria, da história e dos corpos de suas criaturas. O evento da interioridade de Deus, mediante Seu Espírito, no coração mesmo de suas criaturas, impede toda e qualquer bipolaridade rígida e excludente entre transcendência e imanência. A profissão de fé no Deus trino e uno propicia aos cristãos, portanto, uma peculiar relação entre transcendente e imanente: nem pura transcendência, nem mera imanência, mas a celebração da transparência divina na trama da Criação.

\section{Referências}

ARNOULD, J. Darwin, theilhard de chardin et cie. Bruges: Desclé de Brouwer, 1996.

ARNOULD, J. La théologie après Darwin: éleménts pour une théologie de la création dans une perspective évolucionniste. Paris: Cerf, 1998.

BEHE, M. Darwin's black box: the biochemical challenge to evolution: Franklin: The Free Press, 1996.

BOFF, L. Ecologia: grito da terra, grito dos pobres. São Paulo: Ática, 1995.

CAPRA, F.; STEINDL-RAST, D. Pertencendo ao universo: explorações nas fronteiras da ciência e da espiritualidade. São Paulo: Cultrix; Amaná, 2000.

CHARDIN, P. T. de. Hino do universo. A missa sobre o mundo. Cristo na matéria. Três histórias no estilo de Benson. A potência espiritual da matéria. São Paulo: Paulus, 1994. (Coletânea de 5 textos). 
COMBATER a mudança climática: solidariedade humana num mundo dividido. Relatório do Pnud 2007-2008. Disponível em: <http://www.unisinos. br/ihu/ index.php?option=com_noticias\&Itemid=18\&task $=$ detalhe\&id=10991 $>$. Acesso em: 28 nov. 2007.

DAWKINS, R. Deus, um delírio. São Paulo: Companhia das Letras, 2007.

DEMSKI, W. Intelligent design: the bridge between science \& theology. Downers Grove: InterVersity Press, 1999.

HAUGHT, J. F. Deus após Darwin: uma teologia evolucionista. Rio de Janeiro: José Olympio, 2006.

INTERGOVERNMENTAL PANEL ON CLIMATE CHANGE - IPCC. Mudanças climáticas. 2007. Disponível em: <http://www.ipcc.ch/meetings/ sessions-ipcc-wg.htm>. Acesso em: 18 jul. 2007.

JOÃO PAULO II. Ecclesia de eucharistia. São Paulo: Paulinas, 2003.

KÜNG, H. O princípio de todas as coisas: ciências naturais e religião. Petrópolis: Vozes, 2007.

LAMBERT, D. Sciences et théologie: les figures d'un dialogue. Bruxelles: Lessius, 1999.

MESTERS, C.; OROFINO, F. Novos céus e nova terra, vida no campo e na cidade. A sustentabilidade da vida e a espiritualidade. In: CONGRESSO ANUAL DA SOCIEDADE DE TEOLOGIA E CIÊNCIAS DA RELIGIÃO SOTER, 21., 2008, São Paulo. Anais... São Paulo: Paulinas, 2008. p. 11-21. Disponível em: <http://ciberteologia.paulinas.org.br/portals/44/ LivroDigital.pdf>. Acesso em: 13 mar. 2009.

MOLTMANN, J. Ciência e sabedoria: um diálogo entre ciência natural e teologia. São Paulo: Loyola, 2007.

REIMER, H. Toda a criação: bíblia e ecologia. São Leopoldo, RS: Oikos, 2006. 
TAVARES, S. Eucaristia: pluralidade de dimensões na unidade do Mistério, Revista Eclesiástica Brasileira, Petrópolis, v. 63, n. 3, p. 807-828, 2003.

TAVARES, S. Trindade e criação. Petrópolis: Vozes, 2007.

TAVARES, S. A criação na perspectiva ecológica: a contribuição de Scotus. Revista Eclesiástica Brasileira, Petrópolis, v. 68, n. 4, p. 772-806, 2008.

WILSON, E. O. A criação: como salvar a vida na terra. São Paulo: Companhia das Letras, 2008.

ZIZIOULAS, I. A criação como eucaristia: proposta teológica ao problema da ecologia. Florianópolis: ITESC, 2001.

Recebido: 13/04/2009

Received: 04/13/2009

Aprovado 02/05/2009 Approved: 05/02/2009

Revisado: 16/07/2009 Reviewed: 07/16/2009 